\title{
Editor citation: An alleged instance of social-professional desirability
}

\author{
Haim Levy, Ying Sophie Huang ${ }^{1}$, Avner Wolf², Yuval Wolf ${ }^{3 *}$ \\ Hebrew University of Jerusalem, Jerusalem 91905, 2Bar-llan University, Baruch College, ${ }^{3}$ Bar-Ilan University, 52900 Ramat Gan, Israel, \\ ${ }^{1}$ Northern Kentucky University, Highland Heights, KY 41099, City University of New York, New York, NY 10010, USA
}

\begin{abstract}
One of the main pillars of the academic sphere is publication of articles, the scientific purity of which should be as higher as possible. Allegedly, scientists may prefer to cite journal editors more frequently than they would do when those personae are not in editors' position, and quite a few of the formers in quite a few instances do not seem to refuse to go along with. The viability of this sort of assertion is supported by an exploratory examination through a cross-disciplinary scanning of long-term empirical evidence from leading journals in 11 research fields. This analysis covered a total of 337 journal editors from 35 top disciplinary journals spanning 40 years. The findings seem to support the alleged trend called "editor citation". Three psychology journals appear less susceptible to such desirability. Possible accounts are suggested with a special reference to the hypothesis of moral/social modularity. ${ }^{[1]}$
\end{abstract}

Keywords: Editor citation, moral-professional dilemma, moral/social modularity

\section{INTRODUCTION}

Imagine a young scientist dreaming of success and fame who has a manuscript of what hef or she believes to be a brilliant scientific composition. Assumingly, sometimes his or her more experienced colleagues volunteer a practical tip - choose a reputable journal and do not forget to cite the editor. ${ }^{[2,3]}$ Presumably, some young (and possibly older) scientists may experience a moral-professional dilemma in related occasions, knowing that such veterans' advices are incompatible with the substantive scientific command called objectivity, which means transparency and avoidance of circularity, in-breading, etc.

On the other bank of that river, journal editors might presumably sense a moral-professional dilemma as

*Address for correspondence:

E-mail: yuval.wolf@biu.ac.il

\begin{tabular}{|l|l|}
\hline \multicolumn{2}{|c|}{ Access this article online } \\
\hline Quick Response Code: & Website: \\
\hline & www.jscires.org \\
\cline { 2 - 3 } & \\
\hline
\end{tabular}

well. From a professional perspective, he or she should be familiar with the objectivity command. Personally, however, a human being is but a human being, having a desire for more and more success and fame, that is, more citations. From a standpoint of such a two-fold dilemma a straightforward and countable reflection of this issue, that is, editor citation, is explored empirically in this study in three consecutive terms of one's service as a chief editor of a leading journal - preeditorship, editorship, and post editorship.

Editors can choose or determine the references for papers submitted for publication. The editor, either formally or informally, communicates with the referees regarding the status of the submitted paper and has a final say about either the rejection of a paper, or its' R and R (revise and resubmit). Following the final referees' reports, he or she eventually makes the ultimate decision about acceptance or rejection of the paper for publication in the journal.

The decision to accept a paper for publication may involve reasons beyond just the quality of the paper, whether or not the paper fits the journal agenda and recent trends of the journal. What is called peer review among some academic journals is seemingly performed by committees 
with general competence rather than with the specialist's insight that is needed to assess primary research data. Committees might tend, therefore, to resort to secondary criteria such as crude publication counts, journal prestige, the reputation of authors and institutions, and estimated importance and relevance of the research field, making peer review an allegedly imperfect process.

There are indications that some highly ranked academic journals tend to be subject to self-citation bias as the journal editors try to improve the impact factors and its journal ranking. Take for example economics and business administration journals. There are empirical indications as follows: Most articles published in eight top-tier economics journals have a significant tendency to cite other articles published in the same journal, and editorial board members in three of the top finance journals, Journal of Finance, Journal of Financial Economics (JFE), and Review of Financial Studies, are more likely to publish in the journals where they serve as editorial board members. There are also indications that a reputable journal in the field of finance is likely to select for publication research done by someone from an elite finance program and top-ranked journals witness higher authorship concentration from top finance departments.

As such, the editors could steer the direction of the journals and the papers they would like to accept for publication in the journals based on their vision about the future identity of the journals or other considerations. They all know that the editorial period is bounded and in most cases lasts only for a few years. Therefore, based on their positions and the power in the process of accepting papers for publication in their journal, they have a tempting opportunity to enhance self-visibility by accepting papers that cite their own research, while being the journal editors.

In most journals, editors are elected for their positions. The editors of top academic journals are typically well-known authorities in their fields due to previous renowned publications and due to prior involvement in disciplinary associations. The power of the editorship may significantly help the editor in enhancing his/her name in the academic field and also outside the academic world that might bring some other pecuniary benefits.

Moreover, a recent trend in academia to measure academic success, besides the number of publications and the journals where the papers were published, is the number of citations in leading academic journals of the general field of publication (economics, finance, physics, medicine, etc.). For instance, Zsindely et al. ${ }^{[4]}$ study the citation records of the editors-in-chief and all members in the editorial boards for the journals in the field of chemistry. They concluded that there was a strong positive correlation between the mean citation frequency of the editorial board and the impact factor of the journal. Their data suggests that an editor-in-chief with a higher citation frequency leads to a higher impact factor and that editorial board changes should also have an effect.

Citation analysis is based on the assumption that if an author cites a journal article, he or she has found it useful, and therefore the more frequently an article is cited, the greater its role in the scholarly communication process. Researchers who intend to submit their papers for publication in the leading journals, have a strong incentive to change or modify their research topic, such that citing the editor's published papers will be possible. In addition, the implied possibility that citation of the editor (not inevitably the scientific quality of the paper) could play an important role in the editor's decision to accept the paper for publication. This affect the impartial quality as well as the nature of academic research process and make questionable the promotion process in academic institutions that is almost solely based on publication. An editor may not be oblivious to the citations of his/her own papers in a paper that is submitted for publication to his/ her journal. After all, he/she will be the editor in chief for only a limited time period.

If indeed it is the case as our aforementioned contention about the conflict of interest and the non-impartial process of accepting/rejecting papers by academic journals, the citation of editors' research might be artificially inflated and thus un-proportionately increases the editor's research visibility compared to other researchers in the same field. Not only Nobel Prize winners are among them but also the quantity of one's publications does not necessarily guarantee high citation frequency due to the fame factor. May ${ }^{[5]}$ also argues that citations could be biased in favor of certain authors, namely the popular ones who enjoy a "halo effect" in the field of science.

Nevertheless, from the basics of science it derives that there should not be any other acceptance criteria, but the necessary requirements from manuscripts submitted to editors to be considered for publications. Journal editors are nominated to serve as science's gatekeepers. Psychologically, however, the mechanism of publications in refereed journals sets a 
stage for two-party tango - manuscript submitters, who are eager to publish (or else parish), and editors, who are supposed to play the role of gatekeepers of the desired paradise, that is, their journals. Being a human being, a member of each party is assumed to experience a slightly different moral-professional dilemma. For both parties, one hand of the scale is the scientific command (value) of objectivity, while the other side is pragmatics- publish or perish for manuscript submitters and more citations, that is, success and fame, for editors.

This issue has already been studied recently under the title of "Flattery citation" ${ }^{[4,5]}$ (e.g. Frandsen and Nicolaisen, 2010). ${ }^{[6]}$ We prefer, however, the title "Editor citation", to avoid the judgmental connotation embedded in the term "Flattery". Laband et al. ${ }^{[7]}$ citations of editors and board members of the American Economic Review in articles appearing in that journal. The recorded rate of publications in the journal since 1985 was compared with the beholders' rate in two "control" journals. The only noticeable difference was found in the year 2000.

Frandsen and Nicolaisen (2010) ${ }^{[6]}$ sampled four LIS journals and focused on citations of editors and members of editorial boards. The authors concluded that the results reject the flattery citations hypothesis. However, they state that both studies- Laband's and their own- "are highly dependent on the choice of journals as reference samples." To promote a more valid answer to the due question they conducted another study that mainly differed from the formers in the two terms: (1) Taking a sample of three leading economics journals: The American Economic Review, the Journal of Political Economy and the Quarterly Journal of Economics; (2) Using an estimator called "difference-in-differences". ${ }^{[8-10]}$ Frandsen and Nicolaisen ${ }^{[6]}$ declare a further rejection of the flattery citations hypothesis. Nevertheless, the following conclusion appears at the end of their discussion: “....more studies are obviously needed to investigate whether our conclusions are valid for all disciplines." ${ }^{[5]}$

As recommended by these authors, we attempted to establish an empirical basis for a wide-ranging examination of this issue by extending the sample to leading journals from a variety of disciplines. We did not, however, accept the (too?) sophisticated manipulation of the original data, called "difference-in-differences," assuming that an inclusive exploration of the issue should be focused on original numbers deliberated to represent editor citation. Difference-in-differences may form an obscure picture of the results due to computational assumptions which might push the results too far from their origins, based on one out of several possible assumptions, making data treatment too conservative for an exploratory study. We believe that sophisticated data manipulation should be conducted, if at all, if the findings look vague, that is, expose only trees, not a forest.

In the present study, citation patterns for a variety of disciplines were explored over three distinctive time periods - preeditorial, editorial and posteditorial. The findings point to some relationship between the first two periods. Out of the eleven research fields which were sampled in this study, ten witness substantial hikes in editors' citations, the highest being around 300\%. There are, though, two exceptions - Nature and Science that belong in the multidisciplinary category. Editors' citations in the majority of the disciplines reflect a steady decline in the posteditorial period. $A d$-hoc accounts and reservations are offered at the closing chapter of this composition, with a special reference to Wolf's ${ }^{[1]}$ hypothesis of moral modularity which is affiliated with Anderson's ${ }^{[11]}$ theory of functional cognition.

\section{EMPIRICAL ANALYSIS}

The citation patterns of 337 journal editors in a total of 35 top disciplinary journals, spanning 40 years from 1967 to 2007 , were explored. Investigating top journals is in line with Hardin et al., ${ }^{[10]}$ which argue that the research achievement of editorial board members in finance is primarily measured by publishing in the top three journals. In particular, Journal of Finance, the official publication of American Finance Association appears to serve as a gatekeeper for selection to a top tier finance journal editorial board with the vast majority of editorial board members having at least one appearance in this journal.

The choice of journals for the present empirical exploration is based on the impact factors provided by the Journal Citation Reports from the Institute of Scientific Information (ISI), a division of Thomson Scientific. The impact factor is calculated as the ratio of the number of citations of the previous 2 years of the journal divided by the number of articles published in those years, and it is essentially the mean number of recent citations per article. The number of citations for the editors of each journal is retrieved from the Social Sciences Citation Index and the Science Citation Index through the ISI Web of Knowledge database compiled by Thomson Scientific. 
A set of 11 categories is established here as buckets and the journals are allocated to the relevant buckets. As indicated by Stigler, ${ }^{[13]}$ by aggregating the individual journals into categories of discipline some of the major sources of variation can be avoided. For example, some papers attract many early citations but are subsequently ignored, while others are noticed only slowly and achieve their peak of acknowledged influence after many years. This approach can also avoid some technical problems, such as multiple authors.

The first category is Economics and Finance, and it includes six journals: Econometrica, Journal of Finance, JFE, Journal of Financial Economics, Quarterly Review of Economics and Review of Financial Studies. The journals of Economics and Finance are combined here because they are two closely related areas where researchers in each of the two disciplines very often write and publish papers in both areas. The second category is Sociology, and it contains three journals: American Sociological Review, Annual Review of Sociology and American Journal of Sociology. The third category is Statistics, and three journals are considered: Journal of Royal statistical Society, Journal of American Statistical Association and the Analysis of Statistics. The fourth category is Political Science, and it includes three journals: American Political Science Review, American Journal of Political Science and Journal of Conflict, resolution. The fifth category is Psychology (multi-disciplinary), and the three journals are: Annual Review of Psychology, Psychological Bulletin and Psychological Review. The sixth category is Mathematics, and it includes three journals: Bulletin of the American Mathematical Society, Communication on Pure Applied Mathematics and Acta Mathematica. The seventh category is Biology (multi-disciplinary), which includes three journals, namely, FASEB Journal, Bioessays and Biological Reviews.
The eighth category is Chemistry (multi-disciplinary) and the three journals considered are: Chemical Reviews Accounts of Chemical Research and Chemical Society Reviews. The ninth category is Physics (multi-disciplinary) and it contains three journals: Review of Modern Physics, Physical Review Letters and Physical letters B. The tenth category is Medicine (multi-disciplinary) and it includes three journals: New England Journal of Medicine, Journal of American Medical Association and Lancent. The eleventh category of multidisciplinary sciences includes two prestigious science journals: Nature and Science [Details of years covered and the number of editors included for each journal are included in the Appendix]. A presentation of the overall (grouped) trend is illustrated in Figure 1. An indexe of mean citation is adopted and as such the lines in the figures start from a value of 1 , which is the baseline for year - 3 (3 years prior to the editorial period).

It should be noted that various editors serve in this position for periods of various lengths, hence there is no common number of years that can be referred to as the editorial period. Therefore, the mean number of citations is calculated per 1-year of the editorial period. Accordingly, the citation index number above the letter " $E$ " (This letter is used to indicate the editorial period) is the mean citation index per editor per year of all journals when all the years that those included in the present sample serve as editors are taken into account. An index of mean citations is adopted here and as such the line starts from a reading of 1 , which is the baseline year, or 3 years prior to the editorial period.

It is clear that the number of citations increases from the preeditorial through the editorial period, reaching its peak 1 -year after the editor steps down, then gradually declines for each of the following years in the posteditorial period.

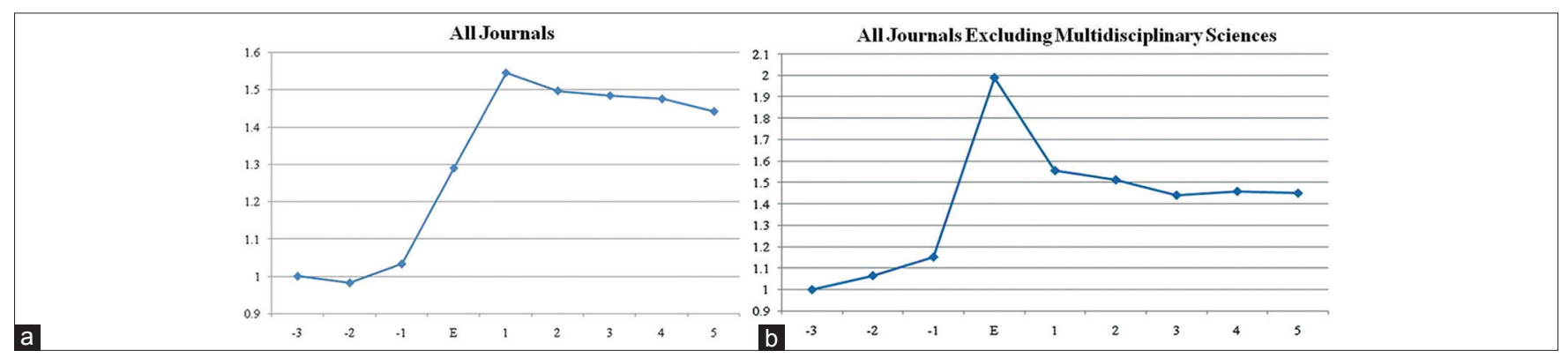

Figure 1: Mean citation index patterns. (a) All the journals are used to compute the citation index. (b) The citation index is recomputed when the category of multidisciplinary sciences is excluded. The vertical axis shows the standardized citation index per editor per year. On the horizontal axis, "-3", “-2" and "-1" stand for the 3 years, 2 years, and 1-year before the editorial period, respectively; the letter "E" stands for the "editorial period"; and " 1 ", "2", “ 3 ", "4" and " 5 " stand for the one to 5 years after the editorial period, respectively 
This diagram indicates that there is a significantly positive editor effect on citations. In Table 1 the category of multidisciplinary sciences is excluded from the calculation because their unique style and feature induce different citation patterns. Once this category is eliminated from the sample, the editor effect becomes much more visible as the peak of the citation is observed during the editorial period, that is editors' work is mostly cited when they serve as the editor in chief of a journal.

In Figure 2a-c, the mean citation indexes is plotted by combining the categories into three subgroups. In Figure $2 \mathrm{a}$, we show the mean citation indexes for the disciplines in social sciences, where an editor effect is detected in Economics and Finance, Politics and Sociology. In Figure 2b, there is an increase in citations for Math, Physics and Statistics from preeditorship years to the editorial period. However, for Statistics and Math mean citations keep rising for another few years in the posteditorial period, while for Physics we can see a decline in the mean citation starting the $2^{\text {nd }}$ year in the posteditorial period. In reality, it is not uncommon to take years for a paper to go through the review process, multiple revision processes and eventually come out in print. In Figure 2c, although differing in magnitudes, increases in the mean citation index are observed for Chemistry, Biology and Medicine. Furthermore, it is interesting to observe the big jump in the mean citation in Nature and Science 1-year after the editorial period. This may be contributed to a bit longer timeframe for papers to be published in multidisciplinary sciences, hence the lag effect. In this subgroup, there is though a clear pattern in the posteditorial period that the mean citation indexes all tend to go down over time. The background descriptive statistics are presented in Table 1.

Table 1: Descriptive statistics of the sample

\begin{tabular}{lcccc}
\hline Category & $\begin{array}{c}\text { Number } \\
\text { of } \\
\text { journals }\end{array}$ & $\begin{array}{c}\text { Number } \\
\text { of } \\
\text { editors }\end{array}$ & $\begin{array}{c}\text { Number } \\
\text { of } \\
\text { maximum } \\
\text { years }\end{array}$ & $\begin{array}{c}\text { Mean } \\
\text { editorial } \\
\text { period } \\
\text { (in years) }\end{array}$ \\
\hline Economics and finance & 6 & 72 & 40 & 6.85 \\
Biology & 3 & 18 & 38 & 6.94 \\
Chemistry & 3 & 26 & 40 & 9.73 \\
Math & 3 & 29 & 40 & 5.45 \\
Medicine & 3 & 28 & 40 & 10.18 \\
Physics & 3 & 46 & 40 & 11.59 \\
Politics & 3 & 26 & 40 & 5.00 \\
Psychology & 3 & 23 & 40 & 6.17 \\
Sociology & 3 & 25 & 40 & 4.32 \\
Statistics & 3 & 36 & 38 & 3.39 \\
Multidisciplinary sciences & 2 & 8 & 48 & 11.63 \\
\hline
\end{tabular}

Each category in Table 1 denotes the number of journals, the total number of editors, the number of maximum years of the editorship included and the mean editorial period. The smallest number of mean editorship is 3.39 years in statistics, and the longest mean editorial period is in multidisciplinary sciences, which lasts a mean of 11.63 years. The category of Economics and Finance has 6 journals as the researchers in each of the two disciplines very often publish papers in both types of journals. The mean editorial period for all journals is 6.9 years.

For each journal the mean citation index is standardized using the number of citations for a year, 3 years before the editorial period, as a benchmark and set it to 1 . Table 2 presents each journal's mean citation index per editor per year during the editorial period. The change in the mean citation index from the preeditorial period to the editorial period can be easily computed. For example, for Quarterly Journal of Economics (QJE) the mean citation index for the editorial period is 7.87. Compared to the preeditorial period, there is an increase of 6.87 in the mean citation index (7.87-1.00). This means that there is an increase of $687 \%$ in the mean editors' citation from the preeditorial period to the editorial period for the QJE. Among the finance journals, JFE also experiences a tremendous increase of $638 \%$ from the preeditorial period.

Based on the changes of the mean citation indexes there seems to be strong editorial effects. For some journals the change appears to be fairly high, like 6.87 for QJE, while for others, like Psychological Review it is smaller (+0.11). Most of the changes, however, are positive, implying that being an editor of a journal enhances one's citations.

Sign tests were used to decide whether or not the positive changes of mean citation index per editor per year for the editorial period from the preeditorial period are [Table 2] significant. It can be noted that this inferential tool can test the hypothesis that there is no difference between the continuous distributions of two random variables $\mathrm{X}$ and Y. This hypothesis implies that given a random pair of measurements $\left(x_{i}, y_{i}\right)$, then $x_{i}$ and $y_{i}$ are equally likely to be larger than the other. The probabilities of no change in the sign under each of the four tests are basically zero.

The results of four different sign tests are presented in Table 3. The first one is a test for the exact change of sign - exact binomial test; the second one is a test of a change of sign based on normal approximation; the third is Wilcoxon test for signed ranks and the fourth is van der Waerden test for normal scores. All four tests point out 


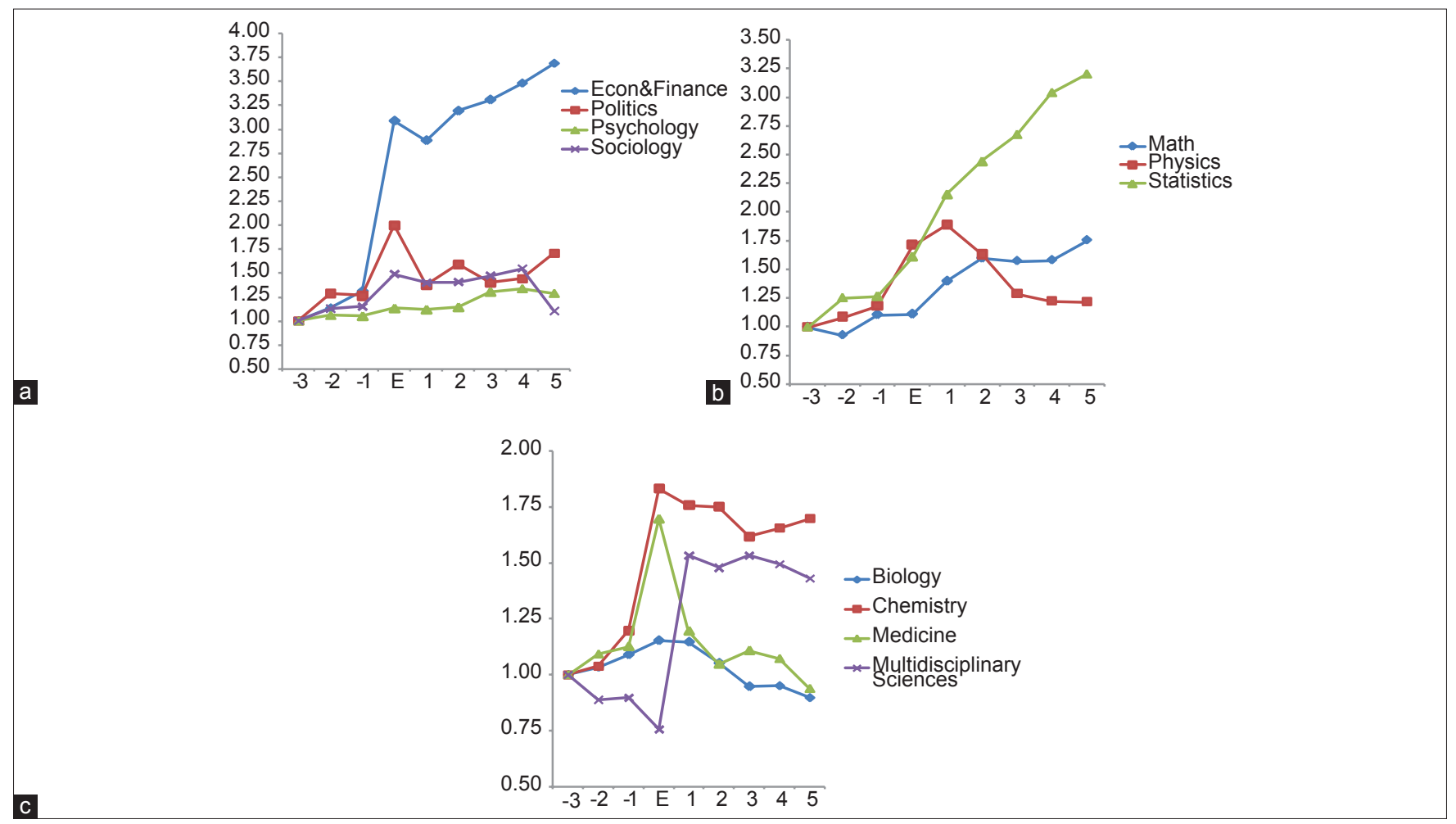

Figure 2: Mean citation index for three subgroups. The vertical axis shows the standardized citation index per editor per year. On the horizontal axis, "-3", "-2" and "-1" stand for the 3 years, 2 years, and 1-year before the editorial period, respectively; letter "E" stands for the "editorial period"; and "1", “2", “3", "4" and " 5 " stand for the one to 5 years after the editorial period, respectively. (a) Subgroup I (Social Sciences). (b) Subgroup II. (c) Subgroup III

that the changes in the signs are significant (The probability of no change in the sign under each of the four tests is basically zero). As a result, the null hypothesis that the median of our sample is 0 , that is, no change in the sign, is rejected. This seems to support the presumption of editor effect for most of the journals.

Table 4 reports the mean citation indexes for different categories instead of journals. Similar to Table 2, it shows the mean citation index during the editorial period. For example, for the Economics and Finance group, there is a mean citation index of 2.81. Since the index for the preeditorial period is set to 1 , a change from the preeditorial period to the editorial period is 1.81 (2.81-1.00). Sign test results that are based on the changes in the index reported in Table 4 are presented in Table 5.

These tests examine whether or not the positive changes of mean citation index per editor per year for the editorial period from the preeditorial period are significant. As in the previous case [Table 3], all four tests show that the changes in signs are significant and strong positive editor impact on editors' citations is detected as well for different categories.
Table 6 displays the mean citation index for three sub-periods corresponding to: (1) The period of 3 years prior to the editorial period, (2) the editorial period, and (3) the 3 years post the editorial period for all 35 journals in our data. Like in previous tables, the indexes are standadized, and the preeditor period index is set to 1 for all journals. Obviously, it is of interest to find if there is any linkage between the citation indexes in the three sub-periods. While in almost all journals there is a significant increases in editors' citations from the first to the second period, in most (26 out of 35 ) journals there is still a positive trend from the second to the third period. It needs to be acknowledged that it takes time to get a paper published in a top academic journal. A paper may be submitted when $\mathrm{XYZ}$ is the editor, but it takes anywhere from 1 to 3 years before the paper is officially accepted and published, by which time XYZ editor has already stepped down from his position.

To test whether the changes in the mean citation indexes are materially different, the null hypothesis implies that the means of column 1 (mean citation 3 years before editorial period) and column 2 (mean citation during editorial period) are the same. Based on the results in Table 7 the 
Levy, et al.: Editor citation

Table 2: Journal mean citation index for the editorial period

\begin{tabular}{|c|c|c|}
\hline \multirow[t]{2}{*}{ Journal name } & \multicolumn{2}{|c|}{$\begin{array}{c}\text { Citation } \\
\text { index }\end{array}$} \\
\hline & Mean & SD \\
\hline Quarterly Journal of Economics & 7.87 & 8.66 \\
\hline Journal of Political Economy & 1.57 & 1.24 \\
\hline Econometrica & 1.38 & 1.15 \\
\hline Journal of Finance & 3.10 & 2.99 \\
\hline Journal of Financial Economics & 7.38 & 3.42 \\
\hline Review of Financial Studies & 1.44 & 1.31 \\
\hline American Sociological Review & 1.60 & 1.05 \\
\hline Annual Review of Sociology & 1.44 & 1.05 \\
\hline American Journal of Sociology & 1.13 & 1.12 \\
\hline Journal of Royal Statistical Society & 1.66 & 1.57 \\
\hline Journal of the American Statistical Association & 1.50 & 2.18 \\
\hline The Annals of Statistics & 1.22 & 0.82 \\
\hline American Political Science Review & 1.73 & 1.76 \\
\hline Acta Mathematica & 1.70 & 0.36 \\
\hline American Journal of Political Science & 1.33 & 1.09 \\
\hline Journal of Conflict Resolution & 2.50 & 1.70 \\
\hline Annual Review of Psychology & 0.66 & 1.08 \\
\hline Psychological Bulletin & 1.41 & 1.13 \\
\hline Psychological Review & 1.11 & 0.54 \\
\hline Bulletin of the American Mathematical Society & 0.98 & 0.91 \\
\hline Communications on Pure and Applied Mathematics & 1.70 & 0.36 \\
\hline FASEB Journal & 0.82 & 0.49 \\
\hline Bioessays & 1.33 & 0.22 \\
\hline Biological Reviews & 1.13 & 0.83 \\
\hline Chemical Reviews & 2.53 & 1.29 \\
\hline Accounts of Chemical Research & 2.07 & 1.44 \\
\hline Chemical Society Reviews & 1.14 & 1.46 \\
\hline Reviews of Modern Physics & 1.73 & 1.33 \\
\hline Physical Review Letters & 1.79 & 3.89 \\
\hline Physics Letters B & 1.28 & 1.38 \\
\hline New England Journal of Medicine & 1.12 & 1.26 \\
\hline JAMA & 1.81 & 1.85 \\
\hline LANCET & 2.78 & 4.31 \\
\hline Nature & 1.29 & 1.80 \\
\hline Science & 0.74 & 0.93 \\
\hline
\end{tabular}

$\mathrm{SD}=$ Standard deviation

null hypothesis can be rejected, and it can be concluded that the first two columns are different. A similar test was also conducted on the means of column 2 and column 3 (mean citation 3 years after editorial period) and based on the results in Panel B it cannot reject the null that these two columns are the same.

An ANOVA is carried out as well on the values based on Table 7 to determine if there exists a significant difference between the mean citation indexes per editor per year across 3 time periods and across various journals. Table 8
Table 3: Sign tests on table 2*

\begin{tabular}{lcc}
\hline \multicolumn{3}{c}{$\begin{array}{c}\text { Test of hypothesis: Median=0 } \\
\text { Sample median=0.440 }\end{array}$} \\
\hline Method & Value & Probability \\
\hline Sign (exact binomial) & 31 & 0.00 \\
Sign (normal approximation) & 4.395 & 0.00 \\
Wilcoxon signed rank & 4.595 & 0.00 \\
Van der Waerden (normal scores) & 4.399 & 0.00 \\
\hline \multicolumn{4}{c}{ Median test summary } \\
\hline Category & Count & Mean rank \\
\hline Obs $>0.00$ & 31 & 19.226 \\
Obs $<0.00$ & 4 & 8.5 \\
Obs $=0.00$ & 0 & \\
\hline
\end{tabular}

*The reported sign test results are based on the change of the mean citation index in the editorial period from the preeditorial period. The change of the index from the preeditorial period is the number in the second column less than " 1 ", because the mean citation index in the preeditorial period is set to " 1 " as the benchmark. The question is whether or not the positive changes of the mean citation index per editor per year for the editorial period from the preeditorial period are statistically significant

shows the results of a test deliberated to examine the null hypothesis that the mean citation indexes in three columns are the same; based on the significant $F$ value the null hypothesis can be rejected. In other words, the one-way ANOVA reveals an editor effect on the citations between the three sub-periods. What's more, the two-way ANOVA which tests whether there is similarity between the three sub-periods and among the journals simultaneously, points out a similar pattern, as the $F$ statistics are well above the $F$ critical values. Based on the results it is evident that the null hypothesis of no difference between the citation indexes in the three periods and that there is no difference in the citation indexes among the 35 journals should be rejected. It can be concluded that there is a variation in the citation index among the different journals (rows) and among the three sub-periods (columns).

\section{IMPLICATIONS AND POSSIBLE DIRECTIONS}

Publish or perish is the rule that guides young faculty in getting tenure at most universities. Similarly, an academic promotion depends mainly on one's publication record. Out of many papers only few will be published in one of the top rated journals in the corresponding field of research. Depending on the referees' recommendations and the editors' decisions, papers will either be rejected or be admitted for publication. How can one increase the chance of acceptance of his or her paper for publication?

Presumably, the chances of achieving this goal can be increased materially by citing the editor's papers. If indeed this is the case, it has two main negative implications: 1. 
Table 4: Category mean citation index for the editorial period

\begin{tabular}{lcc}
\hline Category & \multicolumn{2}{c}{ Citation index } \\
\cline { 2 - 3 } & Mean & SD \\
\hline Economics and finance & 2.81 & 2.76 \\
Biology & 1.09 & 1.12 \\
Chemistry & 1.70 & 1.41 \\
Math & 1.22 & 1.04 \\
Medicine & 1.40 & 2.29 \\
Physics & 1.51 & 1.91 \\
Politics & 1.67 & 1.42 \\
Psychology & 0.98 & 1.16 \\
Sociology & 1.39 & 1.32 \\
Statistics & 1.41 & 1.41 \\
Multidisciplinary sciences & 0.81 & 1.33 \\
\hline
\end{tabular}

$\mathrm{SD}=$ Standard deviation

Table 5: Sign tests on table 4*

\begin{tabular}{lcc}
\hline \multicolumn{3}{c}{$\begin{array}{c}\text { Test of hypothesis: Median=0 } \\
\text { Sample median=0.400 }\end{array}$} \\
\hline Method & Value & Probability \\
\hline Sign (exact binomial) & 9 & 0.065 \\
Sign (normal approximation) & 1.809 & 0.070 \\
Wilcoxon signed rank & 2.533 & 0.011 \\
Van der Waerden (normal scores) & 2.505 & 0.012 \\
\hline \multicolumn{4}{c}{ Median test summary } \\
Category & Count & Mean rank \\
\hline Obs $>0.00$ & 9 & 6.889 \\
Obs $<0.00$ & 2 & 2.000 \\
Obs $=0.00$ & 0 & \\
\hline
\end{tabular}

*The reported sign test results are based on the change of the mean citation index in the editorial period from the preeditorial period. The change of the index from the preeditorial period is the number in the second column of table $3 \mathrm{~A}$ less " 1 ", because the mean citation index in the preeditorial period is set to " 1 " as the benchmark. We test if the positive changes of the mean citation index per editor per year for the editorial period from the preeditorial period are statistically significant

Researchers may not work on topics which they otherwise think are most important but rather shift to research topics on which the editor has published. 2. If citation of the editor's work is a contributing factor for accepting a paper for publication, it means that there is a biasing element in the academic promotion procedure as well: The citation index of those who seek promotion and were able to publish may be impure due to consideration other than the high quality of the paper to be published.

In line with the recommendation of Frandsen and Nicolaisen, ${ }^{[8]}$ the present exploratory study related to citations corresponding to 337 journal editors of 35 journals in 11 research fields covering the period 1967-2007 (recalling that those authors were sampled from only three journals from one research field). The citation pattern of all editors together was analyzed, and this analysis was refined by studying each
Table 6: Journal mean citation index for three sub-periods*

\begin{tabular}{|c|c|c|c|c|c|}
\hline \multirow[t]{2}{*}{ Journal name } & \multirow[t]{2}{*}{ Before } & \multicolumn{2}{|c|}{ During } & \multicolumn{2}{|c|}{ After } \\
\hline & & Mean & SD & Mean & SD \\
\hline Quarterly Journal of Economics & 1 & 6.48 & 9.03 & 8.96 & 15.87 \\
\hline Journal of Political Economy & 1 & 1.52 & 1.22 & 1.86 & 1.47 \\
\hline Econometrica & 1 & 1.40 & 1.19 & 1.97 & 1.18 \\
\hline Journal of Finance & 1 & 3.10 & 2.99 & 3.03 & 4.06 \\
\hline Journal of Financial Economics & 1 & 8.78 & 3.43 & 3.81 & 4.20 \\
\hline Review of Financial Studies & 1 & 1.33 & 1.28 & 1.82 & 1.93 \\
\hline American Sociological Review & 1 & 1.60 & 1.05 & 1.63 & 1.26 \\
\hline Annual Review of Sociology & 1 & 1.44 & 1.05 & 1.18 & 1.17 \\
\hline American Journal of Sociology & 1 & 1.13 & 1.12 & 1.32 & 0.98 \\
\hline $\begin{array}{l}\text { Journal of Royal Statistical } \\
\text { Society }\end{array}$ & 1 & 1.66 & 1.57 & 1.89 & 1.56 \\
\hline $\begin{array}{l}\text { Journal of the American } \\
\text { Statistical Association }\end{array}$ & 1 & 1.50 & 2.18 & 2.97 & 4.31 \\
\hline The Annals of Statistics & 1 & 1.22 & 0.82 & 1.54 & 0.91 \\
\hline $\begin{array}{l}\text { American Political Science } \\
\text { Review }\end{array}$ & 1 & 1.61 & 0.93 & 1.74 & 0.18 \\
\hline $\begin{array}{l}\text { American Journal of Political } \\
\text { Science }\end{array}$ & 1 & 1.31 & 1.21 & 1.49 & 1.60 \\
\hline Journal of Conflict Resolution & 1 & 2.66 & 2.04 & 2.43 & 2.40 \\
\hline Annual Review of Psychology & 1 & 0.76 & 1.06 & 1.21 & 1.80 \\
\hline Psychological Bulletin & 1 & 1.41 & 1.13 & 1.50 & 1.57 \\
\hline Psychological Review & 1 & 1.11 & 0.54 & 1.02 & 0.68 \\
\hline $\begin{array}{l}\text { Bulletin of the American } \\
\text { Mathematical Society }\end{array}$ & 1 & 0.98 & 0.91 & 1.15 & 1.29 \\
\hline $\begin{array}{l}\text { Communications on Pure and } \\
\text { Applied Mathematics }\end{array}$ & 1 & 1.07 & 0.88 & 1.41 & 1.23 \\
\hline Acta Mathematica & 1 & 1.70 & 0.36 & 2.02 & 0.33 \\
\hline FASEB Journal & 1 & 0.82 & 0.49 & 0.67 & 0.56 \\
\hline Bioessays & 1 & 1.33 & 0.22 & 1.20 & 1.39 \\
\hline Biological Reviews & 1 & 1.13 & 0.83 & 1.27 & 1.27 \\
\hline Chemical Reviews & 1 & 2.00 & 1.66 & 1.93 & 1.49 \\
\hline Accounts of Chemical Research & 1 & 1.71 & 1.00 & 2.03 & 1.31 \\
\hline Chemical Society Reviews & 1 & 1.10 & 1.58 & 1.48 & 1.67 \\
\hline Reviews of Modern Physics & 1 & 1.66 & 1.44 & 1.89 & 2.14 \\
\hline Physical Review Letters & 1 & 0.83 & 0.94 & 1.54 & 1.69 \\
\hline Physics Letters B & 1 & 1.20 & 1.18 & 1.32 & 1.17 \\
\hline New England Journal of Medicine & 1 & 1.52 & 1.25 & 1.89 & 1.31 \\
\hline JAMA & 1 & 1.56 & 1.43 & 1.22 & 1.36 \\
\hline LANCET & 1 & 3.17 & 3.69 & 5.02 & 4.53 \\
\hline Nature & 1 & 1.18 & 1.55 & 1.82 & 1.75 \\
\hline Science & 1 & 0.94 & 0.79 & 1.23 & 0.89 \\
\hline
\end{tabular}

*The mean citation indexes are computed differently from those in table 3. Here, when an editor does not have citations for the three years after the editorial period (for example, he may still serve as the editor of the journal), then he is also excluded from the other calculations

of the research areas separately. The focus was on the mean citations of editors in 3 time periods: Three years before the editorial period, the editorial period and three to 5 years after the editorial period. The results can be summarized as follows: - Overall, the mean number of citation of all 337 editors increases during the editorial period and 1-year after 
that by $50 \%$. After editors stepping down from the editorship, this number slowly decreases

- Eliminating one category, that is multidisciplinary sciences, which has some unique features, the number of citation increases during the editorial period by nearly $100 \%$, and then gradually decreases, getting in the $5^{\text {th }}$ year of the post editorial period to only $50 \%$ more citation in comparison to that of the preeditorial period

- The difference in the number of citations between the editorial period and the preeditorial period is significant. However, in the post editorial period there is a nonsignificant decrease in the number of citations in comparison to that of the editorial period. This can be explained by the fact that some papers which have been accepted for publication during the editorial period are published in delay where the past editors may still have an informal influence, or at least researchers perceive them to be part of the network of past and future editors

- There are differences between the citation patterns of various research fields, but overall the same tendency to cite the editors occur in most research fields.

One can adopt the spirit behind the present exploration and conclude that indeed article writers cite editors and incline to choose topics similar to the editors' research in order to

Table 7: Hypothesis testing on table 6

Panel A: $\mathrm{H}_{0}$ : Column 2=Column 1, $\mathrm{H}_{1}$ : Column 2>Column 1

Test of hypothesis: Mean of column $2=1$

Sample mean of column $2=1.826$

Sample SD=1.575

\begin{tabular}{lcc}
\hline Method & Value & Probability \\
\hline$T$-statistic & 3.103 & 0.004
\end{tabular}

Panel B: $\mathrm{H}_{0}$ : Column 2=Column 3, $\mathrm{H}_{1}$ : Column 2>Column 3

Test of hypothesis: Mean of column 2=2.013

Sample mean of column $2=1.826$

Sample SD $=1.575$

\begin{tabular}{lcc}
\hline Method & Value & Probability \\
\hline$T$-statistic & -0.702 & 0.488 \\
\hline $\mathrm{SD}=$ Standard deviation & &
\end{tabular}

Table 8: ANOVA tests on table 6

\begin{tabular}{lcccccc}
\hline Source of variation & SS & df & MS & $\boldsymbol{F}$ & $\boldsymbol{P}$ & $\boldsymbol{F}$ critical values \\
\hline Panel A: One-way ANOVA & & & & & 0.002 & \\
$\quad$ Between columns & 20.348 & 2.000 & 10.174 & 6.596 & & \\
Within columns & 157.329 & 102.000 & 1.542 & & & \\
Panel B: Two-way ANOVA & & & & & 0.0001 & \\
Rows & 92.101 & 34.000 & 2.709 & 2.824 & 0.0001 \\
Columns & 20.348 & 2.000 & 10.174 & 10.606 & \\
Error & 65.228 & 68.000 & 0.959 & & & 3.132 \\
\hline
\end{tabular}

enhance the chance of publishing their research papers. It can be speculated, however, that the editors are indeed new stars, and they were elected to the editorial position due to their extraordinary research, hence the increase in their citations is justified. Nevertheless, the latter explanation can be rejected because the number of citation tend to decrease gradually in the posteditorial period.

Overall, the findings seem to refute the working null hypothesis that there is no editor citation effect. Most intriguing is the relevance of the issue to all disciplines of science, beyond era and personae. Assuming that the findings reflect a worrisome trend, two anticipatory operative modes can be suggested. One mode is a system oriented while the other relates to the psychological realm.

From a system perspective, the following conclusions can be drawn. The practical value of this trend lies in its immediate relevance to any manuscript to be submitted to any scientific journal and to any acceptance decision made by any editor at any time. This mundane value is of special importance due to the severely jeopardizing potential of the claimed phenomenon.

Theoretically, the basics of the philosophy of science and some substantive psychological conception appear quite relevant to this issue. Undoubtedly, the phenomenon labeled as "editor citation" is counterproductive in terms of the beholders' (manuscripts submitters and editors) ability to keep up necessary scientific standards, especially objectivity, despite the psychological accountability of this sort of over-citation.

A few possible system-oriented ways to attenuate violation of the objectivity command caused by the presumed editor citation effect can be suggested. One proposed step, related to promotion procedures, is to let independent experts read the papers and write a report on the quality of the research. A research index that decreases as the number of citations of the editor increases can be established as well. With this 
index, the author will not cite the editor unless there is an economic justification for such a citation.

A third proposed remedy is to encourage the board of each journal to publish in the journal the annual number of citations of the editor (s), covering 3 years prior to the editorial period up to a few years after the editorial period ends. Can these steps be considered as ideal solutions to the alleged problem? Probably not, and further refinement of these suggestions is called for along with a call for other suggestions.

From a (social) psychological perspective, two role partners are involved in the alleged effect, authors and editors. Each seems to undergo a state of moral-professional dilemma in making request/decision regarding manuscript acceptance. One party's decision to over-cite editors and the other party's choice to ignore this trend seems to signify over-weighting of one side of the moral-professional balance, enhancing success and fame. Such preferences are well accounted for by the hypothesis of moral modularity. ${ }^{[1]}$ According to this hypothesis, a functional cognitive schema ${ }^{[11]}$ is developed in the cognitive system of any person regarding any meaningful aspect of his or her life. This schema functions as a mental balance between two complementary aspects of the related phenomenon, that is, the requirement to publish (or parish) and the desire for success and fame.

Editors seem to hold the key for the $1^{\text {st }}$, out of two, attenuating steps. These personae, like any other human being, seem to be modular morally and socially, as theorized and empirically exemplified by Wolf. ${ }^{[1]}$ It derives from this conceptualization that the practical weighting of the related moral-professional balance in each moment of decision can be inversed. This can be achieved in several ways.

Most liable mean in terms of academic freedom is editors self-modification, based on open discussions in the global scientific community (facilitated, for instance, by this very publication) about violation of the objectivity command that might be caused by editor citation effect. Possibly, salience of the issue might prime the desired reverse of moral-professional weighting preferences. A $2^{\text {nd }}$ step is implied. Who but authors are to be the first to internalize the above-illustrated change in editors' approach. Consequently, they will enjoy from more academic freedom to take own way and make own citation preferences.

A synthesis of both modes of attenuating operation - system and psychological oriented- initiated, implemented, monitored and followed-up by leading scientific organizations is recommendable. Such an operation should maintain a thoughtful balance between two critical scientific values - objectivity and academic freedom. Both parties of the presumed worrisome phenomenon, editor citation, are academically free to make their own choices, that is, who is to be cited (manuscripts authors) and what manuscripts to accept for publication (editors). They might, however, for understandable personal motives and possibly with no culpable decision (especially editors) shift to circularity, attenuating this way the prospect of objectivity.

Synthetic and well balanced all science strategies should be accompanied by procedures of cross-disciplinary hypothesis-testing, deliberated to enable an educated modification of the due applications. Inter-disciplinary differences, for instance, the relatively modest editor citation effect in leading psychological journals and the uniqueness of all-science journals, might provide some insight for such hypotheses.

\section{REFERENCES}

1. Wolf $Y$. Modularity in everyday life judgments of aggression and violent behavior. Aggress and Violent Behav Rev J 2001;6:1-34.

2. Seglen PO. The skewness of science. J Am Sci Inf Sci 1992;43:628-38.

3. Seglen PO. Citation rates and journal impact factors are not suitable for evaluation of research. Acta Orthop Scand 1998;69:224-9.

4. Zsindely S, Schubert A, Braun T. Citation patterns of editorial gatekeepers in international chemistry journals. Scientometrics 1982;4:69-76.

5. May KO. Abuses of citation indexing Science 1967;156:890-2.

6. Frandsen TF, Nicolaisen J. Praise the bridge that carries you over: Testing the flattery citations hypothesis. J Am Soclnf Sci Technol 2011;62:807-18.

7. Laband DN, Tollison RD, Karahan G. Quality control in economic. Kyklos 2002;55:315-34.

8. Ashenfelter $\mathrm{O}$, Card D. Using the longitudinal structure of meanings to estimate the effect of training programs. Rev Econ Stat 1985;67:649-60.

9. Cook TD, Shadish WR Social Experiments - some developments over the past 15 years. Annu Rev Psychol 1994;45:545-80.

10. Imbense GW, Wooldrige JM. Recent developments in the econometrics of program evaluation. J Econ Lit 2009;47:5-86.

11. Anderson NH. Unified Social Cognition. New York: Psychology Press; 2008.

12. Hardin W, Liano K, Fok R. Finance editorial board membership and research productivity. Rev Quant Finance Account 2008;31:225-40.

13. Stinger S. Citation patterns in the journal of statistics and probability. Stat Sci 1994;9:94-108.

How to cite this article: Levy $\mathrm{H}$, Huang YS, Wolf A, Wolf $\mathrm{Y}$. Editor citation: An alleged instance of social-professional desirability. J Sci Res 2014;3:46-56.

Source of Support: Nil, Conflict of Interest: None declared 


\section{Appendix}

\begin{tabular}{lcc}
\hline Category & $\begin{array}{c}\text { Years } \\
\text { covered }\end{array}$ & $\begin{array}{c}\text { Number } \\
\text { of editors }\end{array}$ \\
\hline Economics and finance & $1967-2007$ & 13 \\
Quarterly Journal of Economics & $1967-2007$ & 17 \\
Journal of Political Economy & $1967-2007$ & 8 \\
Econometrica & $1967-2007$ & 11 \\
Journal of Finance & $1971-2007$ & 10 \\
Journal of Financial Economics & $1985-2007$ & 13 \\
Review of Financial Studies & & \\
Sociology & $1967-2007$ & 12 \\
American Sociological Review & $1972-2007$ & 6 \\
Annual Review of Sociology & $1967-2006$ & 7 \\
American Journal of Sociology & & \\
Statistics & $1967-2005$ & 15 \\
Journal of Royal Statistical Society & $1967-2005$ & 9 \\
Journal of the American Statistical & $1970-2005$ & 12 \\
Association & & \\
The Annals of Statistics & $1967-2007$ & 8 \\
Political Science & $1967-2007$ & 15 \\
American Political Science Review & $1967-2007$ & 3 \\
American Journal of Political Science & & \\
Journal of Conflict Resolution & $1967-2007$ & 8 \\
Psychology (multidisciplinary) & $1967-2005$ & 9 \\
Annual Review of Psychology & $1967-2005$ & 6 \\
Psychological Bulletin & & Contd.. \\
Psychological Review & & \\
\hline & & \\
\hline
\end{tabular}

Appendix contd...

\begin{tabular}{|c|c|c|}
\hline Category & $\begin{array}{l}\text { Years } \\
\text { covered }\end{array}$ & $\begin{array}{l}\text { Number } \\
\text { of editors }\end{array}$ \\
\hline \multicolumn{3}{|l|}{ Mathematics } \\
\hline $\begin{array}{l}\text { Bulletin of the American } \\
\text { Mathematical Society }\end{array}$ & $1967-2007$ & 20 \\
\hline $\begin{array}{l}\text { Communications on Pure and } \\
\text { Applied Mathematics }\end{array}$ & $1967-2005$ & 8 \\
\hline Acta Mathematica & $1987-2000$ & 1 \\
\hline \multicolumn{3}{|l|}{ Biology (multidisciplinary) } \\
\hline FASEB Journal & $1984-2005$ & 4 \\
\hline Bioessays & $1981-2005$ & 7 \\
\hline Biological Reviews & $1967-2005$ & 7 \\
\hline \multicolumn{3}{|l|}{ Chemistry (multidisciplinary) } \\
\hline Chemical Reviews & $1967-2007$ & 9 \\
\hline Accounts of Chemical Research & $1967-2007$ & 7 \\
\hline Chemical Society Reviews & $1979-2007$ & 10 \\
\hline \multicolumn{3}{|l|}{ Physics (multidisciplinary) } \\
\hline Reviews of Modern Physics & $1967-2007$ & 9 \\
\hline Physical Review Letters & $1967-2007$ & 12 \\
\hline Physics Letters B & $1967-2007$ & 25 \\
\hline \multicolumn{3}{|l|}{ Medicine (multidisciplinary) } \\
\hline New England Journal of Medicine & $1967-2007$ & 10 \\
\hline JAMA & $1967-2007$ & 11 \\
\hline LANCET & 1973-2007 & 7 \\
\hline \multicolumn{3}{|l|}{ Multidisciplinary Sciences } \\
\hline Nature & $1963-2007$ & 4 \\
\hline Science & $1959-2007$ & 4 \\
\hline
\end{tabular}

\section{Author Help: Online submission of the manuscripts}

Articles can be submitted online from http://www.journalonweb.com/jscires. For online submission, the articles should be prepared in two files (first page file and article file). Images should be submitted separately.

1) First Page File:

Prepare the title page, covering letter, acknowledgement etc. using a word processor program. All information related to your identity should be included here. Use text/rtf/doc/pdf files. Do not zip the files.

2) Article File:

The main text of the article, beginning with the Abstract to References (including tables) should be in this file. Do not include any information (such as acknowledgement, your names in page headers etc.) in this file. Use text/rtf/doc/pdf files. Do not zip the files. Limit the file size to $1 \mathrm{MB}$. Do not incorporate images in the file. If file size is large, graphs can be submitted separately as images, without their being incorporated in the article file. This will reduce the size of the file.

3) Images:

Submit good quality color images. Each image should be less than $4096 \mathrm{~kb}(4 \mathrm{MB})$ in size. The size of the image can be reduced by decreasing the actual height and width of the images (keep up to about 6 inches and up to about $1800 \times 1200$ pixels). JPEG is the most suitable file format. The image quality should be good enough to judge the scientific value of the image. For the purpose of printing, always retain a good quality, high resolution image. This high resolution image should be sent to the editorial office at the time of sending a revised article.

4) Legends:

Legends for the figures/images should be included at the end of the article file. 